\title{
A Multibeam Antenna Array Based on Printed Rotman Lens
}

\author{
Wang Zongxin, Xiang Bo, and Yang Fei \\ State Key Lab of Millimeter Waves, Southeast University, Nanjing 210096, China \\ Correspondence should be addressed to Wang Zongxin; wangzx@seu.edu.cn
}

Received 7 July 2012; Revised 31 December 2012; Accepted 7 January 2013

Academic Editor: Tayeb A. Denidni

Copyright (C) 2013 Wang Zongxin et al. This is an open access article distributed under the Creative Commons Attribution License, which permits unrestricted use, distribution, and reproduction in any medium, provided the original work is properly cited.

\begin{abstract}
A compact printable multibeam antenna array is studied in this paper. The antenna system is composed of a printed Rotman lens and an antipodal dual elliptically tapered slot antenna array; both of the two components are studied, respectively, at first, and then integrated on a single printed circuit board to make up the integrated unit of the multibeam antenna array. Measured results of all components are presented.
\end{abstract}

\section{Introduction}

In modern microwave applications, it is often desired to integrate radar and communication functions such as active/ passive target acquisition, combat identification, weapons guidance, secure point-to-point communications, and active protection into a single complete system $[1,2]$. Antennas capable of supporting multiple simultaneous beams that can be scanned over a wide range are capable of this objective.

In this paper we will study a complete integrated unit that consists of a Rotman lens and a tapered slot antenna (TSA) array for generating multiple beams, and all these structures are integrated on a printed circuit board (PCB).

As we know, the Rotman lens has the advantages of being low-cost, wide band, and simple to fabricate and has been proven to be a useful beamformer for generating multiple beams. Many kinds of Rotman lens have been studied in the past decades, including parallel-plate Rotman lens [3], printed Rotman lens [4-6], graded dielectric substrate Rotman lens [7], and SIW Rotman lens [8]. The most useful lens equations for designing Rotman lenses were initially derived by Rotman and Turner [3], then modified and refined by Katagi et al. [9] and Hansen [10].

The tapered slot antenna (TSA) is also simple to fabricate, of low-cost, and wide-band component. The tapered slot antenna (TSA), which was introduced by Gibson [11] in 1979, is a wide band antenna component and has been used widely in microwave engineering. In [12], three TSA elements with different shapes of the taper including the linearly tapered slot antenna (LTSA), the constant width slot antenna (CWSA), and the Vivaldi (exponential taper) antenna have been studied by Yngvesson and others. Gazit has improved the design of the Vivaldi antenna [13] and presented the design method of the antipodal Vivaldi antenna, which has low input resistance and is easy to be matched to the microstrip feed lines. In this paper the antipodal dual elliptically (ADE) TSA [14] is selected to complete the design, because the ADE-TSA has an antenna characteristic similar to that of the antipodal Vivaldi antenna and is easy to be modeled in the existing simulation software such as HFSS.

\section{Design of the Printed Rotman Lens}

Design parameters of a printed Rotman lens is shown in Figure $1 ; \Sigma_{1}$ and $\Sigma_{2}$ are curves where the beam ports and array ports are arranged, respectively, and the Rotman lens region enclosed by curve $\Sigma_{1}$ and curve $\Sigma_{2}$ is usually printed thin copper layer on the dielectric substrate.

The contour $\Sigma_{1}$ is circular arc and the coordinates of the points on contour $\Sigma_{2}$ are defined by the follow formula [3, 9]:

$$
\begin{aligned}
& x=\frac{-1}{g-a_{0}}\left((g-1) w+0.5 b_{1}^{2} \eta^{2}\right), \\
& y=\frac{b_{1}}{b_{0}} \eta(1-w),
\end{aligned}
$$

where $w=\sqrt{\varepsilon_{\text {eff }} / \varepsilon_{r}}\left(W-W_{0}\right) / F$ and $W, W_{0}, f, \eta, g, b_{1}, a_{0}$ and $b_{0}$ have the same meaning as that in $[3,9]$. 


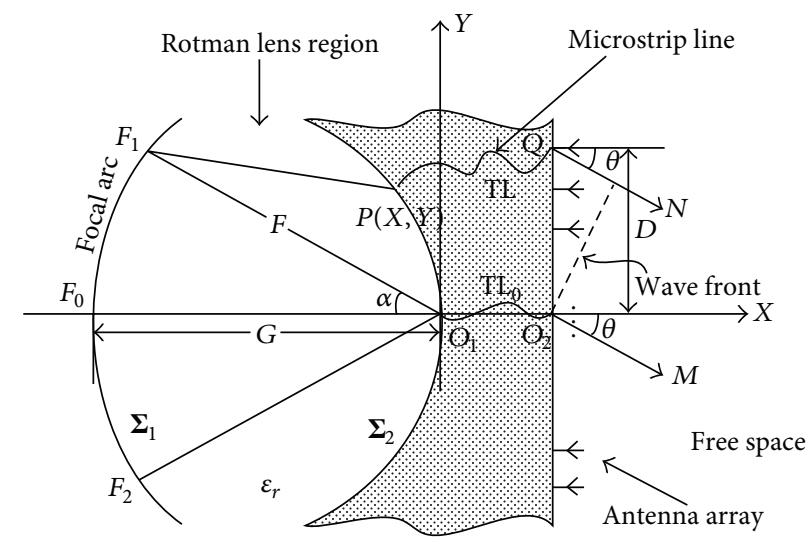

FIgURE 1: Printed Rotman lens parameters.

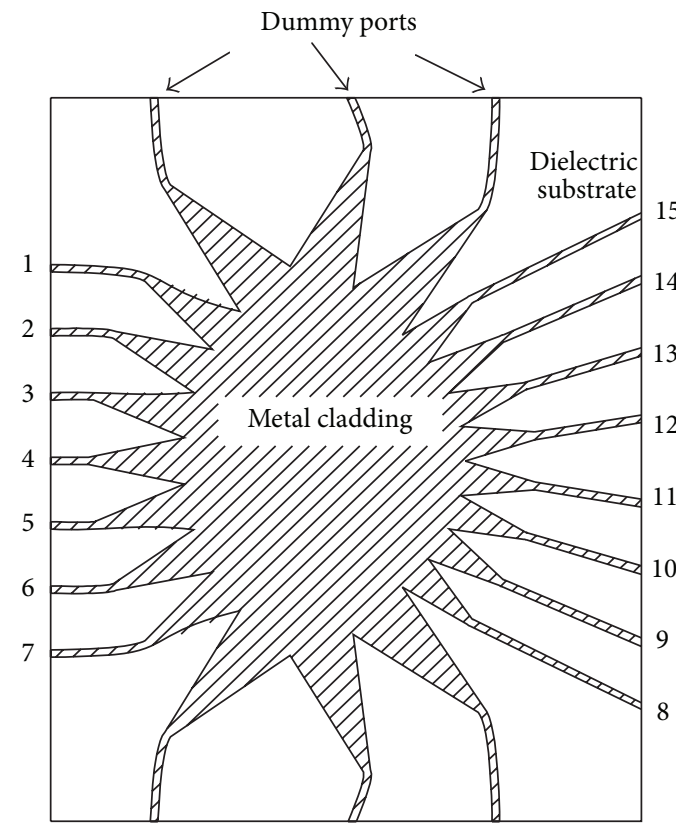

(a) Sketch

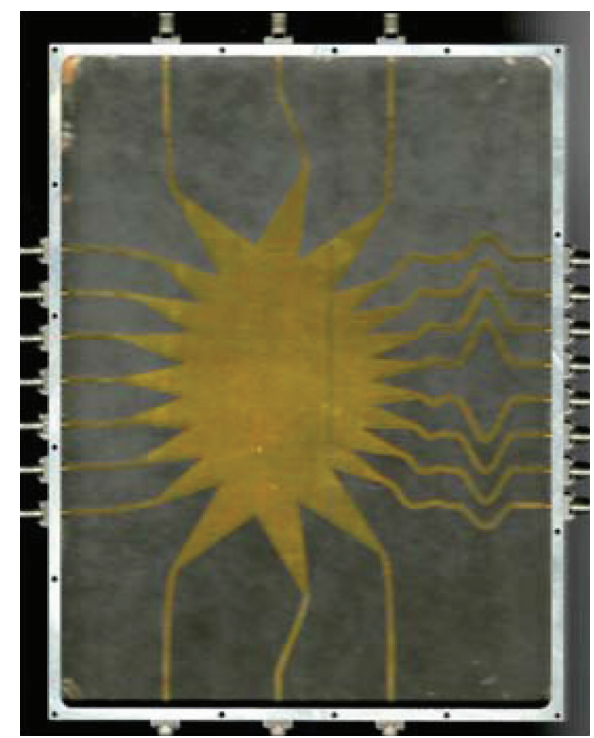

(b) Installed in a metal cavity

Figure 2: Printed Rotman lens.

According the formulas (1) and (2), a printed $\mathrm{Ku}$ band Rotman lens is designed on Rogers RT/duroid 5880 PCB (thickness is $0.508 \mathrm{~mm}$ ). The sketch of the printed Rotman lens for describing the port numbering is shown in Figure 2(a) and the real structure of it is shown in Figure 2(b). Ports 1 7 are used to generate receiving/transmitting beams and are called beam ports. Ports $8 \sim 15$ will be connected to the antenna array and called array ports. The electromagnetic wave should be distributed to all the array ports when incident at one of the beam ports and the power distribution is measured. In the measurement, all the beam ports are terminated with $50 \Omega$ loads except the incident port, and one of the array ports is selected to measure the transmitting parameter; all the other array ports and the dummy ports are also terminated with $50 \Omega$ loads. The measured electromagnetic power distribution results are shown in Figure 3. It can be seen evidently from Figure 3(b) that the distributed phase at the array ports have different linear gradient when incident at different beam port, so beams pointing to different angle will be generated when the array ports of the printed Rotman lens are connected with an antenna array.

\section{Design of the Antipodal Dual Elliptically Tapered Slot Antenna Array}

In this section, designing considerations of the ADE-TSA array will be discussed. An ADE-TSA is shown in Figures 4(a) and 4(b), where the slotline radiator has two arms; the inner and outer edges of the radiator arms are elliptically tapered; that is to say, the two edge of each arm are elliptic curves (see Figure 5). So finally an ADE-TSA depends on four 


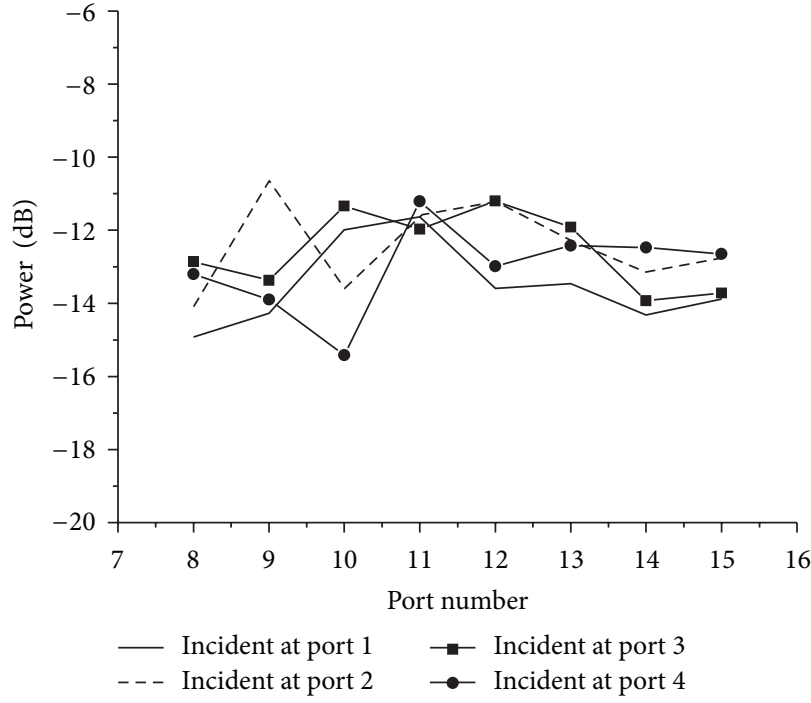

(a) Amplitude distribution

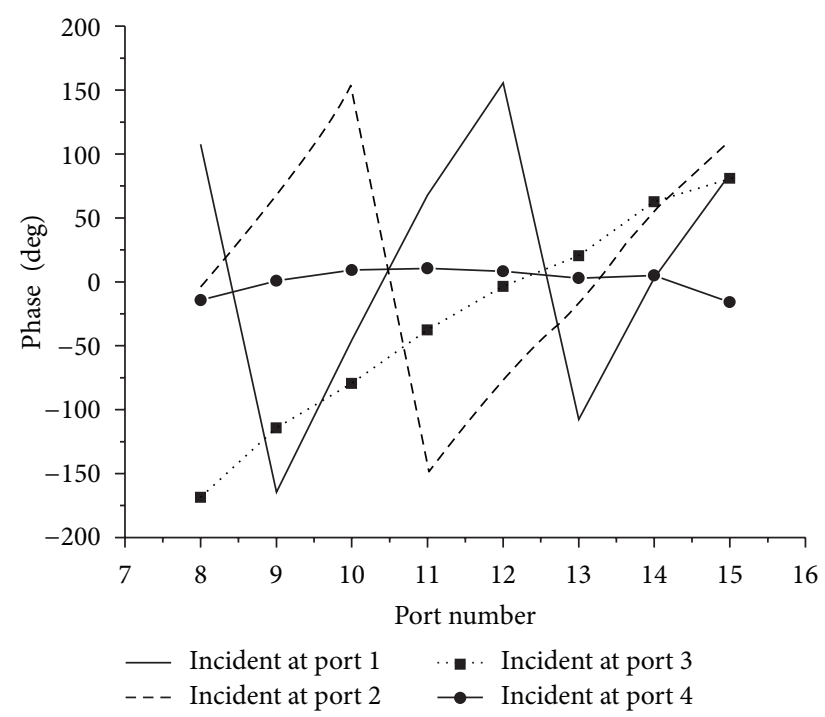

(b) Phase distribution

FIgURE 3: Power distribution at array ports.

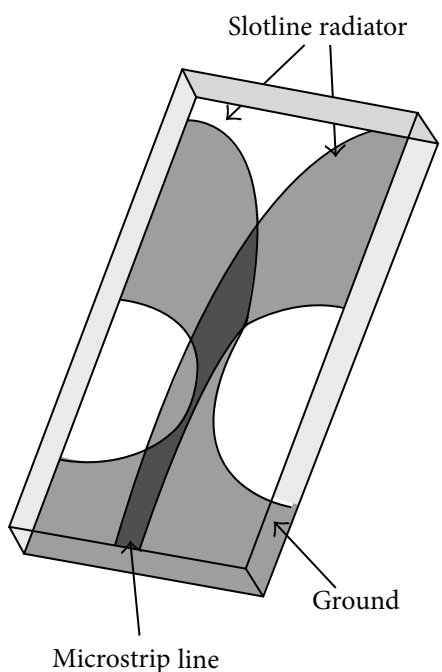

(a) $3 \mathrm{D}$ view

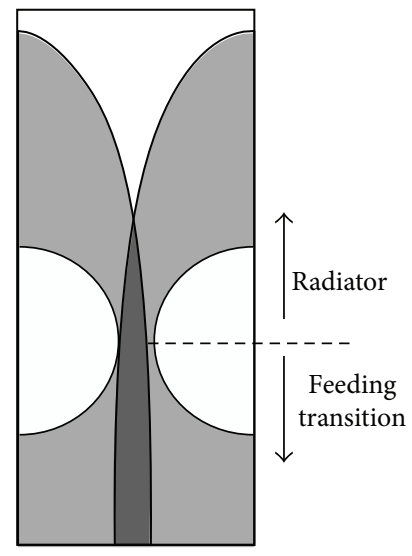

(b) Top view

Figure 4: Geometry of the ADE-TSA.

parameters: $w$ :arm width of the radiator, $l$ :arm length of the radiator, equations of ellipse 1 and ellipse 2.

When arranged in an array, the array element is confined in a space with width of $d$ (see Figure 6) to avoid grating lobes and save space. In our design, the value of $d$ is needed to be $11 \mathrm{~mm}$ or less to match the Rotman lens designed at Ku-band, so for a conventional design, the width $w$ of both of the radiator arms is $5.5 \mathrm{~mm}$, yet it is difficult to obtain a good design with satisfactory standing wave ratio by this arm size. We extended the width $w$ to $6.5 \mathrm{~mm}$; thus the arm of the element 3 on the top of the PCB is partially cascaded with the arm of element 2 on the bottom of the PCB as shown in Figure 6. However, the two arms which make up the partially cascaded area do not touch each other, because they are located at opposite surfaces of the PCB.
An ADE-TSA array is designed according to the construction shown in Figure 6 and then fabricated, where $w=$ $6.5 \mathrm{~mm}, l=10.25 \mathrm{~mm}, d=11 \mathrm{~mm}$, and the equations of ellipse 1 and ellipse 2 are

$$
\begin{aligned}
& \text { Ellipse 1: } \frac{x^{2}}{4.755^{2}}+\frac{y^{2}}{5.706^{2}}=1 \\
& \text { Ellipse 2: } \frac{x^{2}}{15.196^{2}}+\frac{y^{2}}{7.294^{2}}=1 .
\end{aligned}
$$

The ADE-TSA array with 8 elements is fabricated on a PCB (Rogers RT/duroid 5880, thickness is $0.508 \mathrm{~mm}$ ) and assembled in a metal cavity as shown in Figure 7. VSWR values of the ADE-TSA elements are measured and given in 


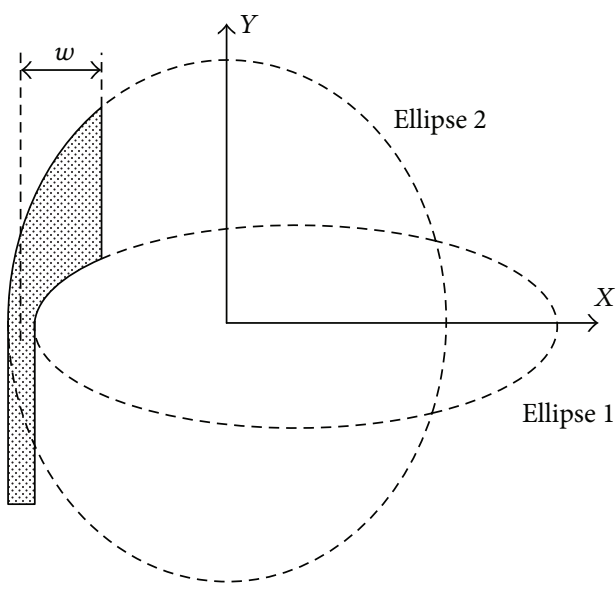

(a) The radiator arm at top side of the PCB

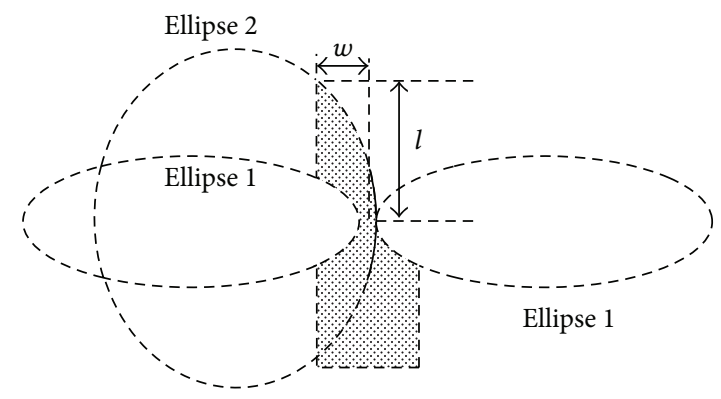

(b) The radiator arm at bottom side of the $\mathrm{PCB}$

Figure 5: Construction of the ADE-TSA.

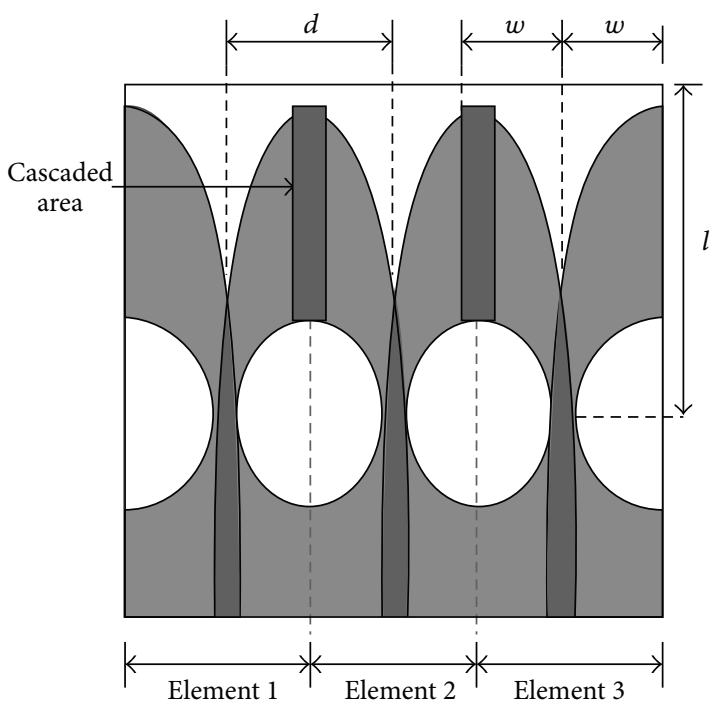

Figure 6: ADE-TSA array.

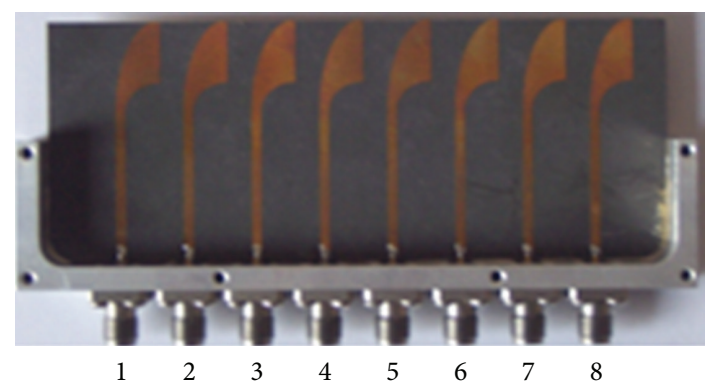

Figure 7: The ADE-TSA array with 8 elements.

Figure 8, and it shows that most VSWR values of all the ports are less than 2 from $13.5 \mathrm{GHz}$ to $18 \mathrm{GHz}$, which is satisfactory.

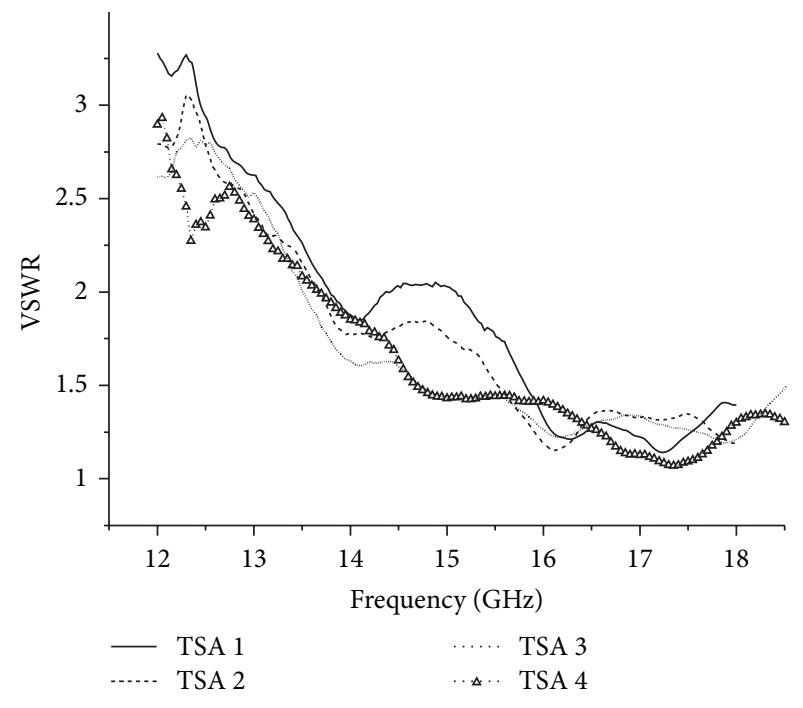

FIgURE 8: Measured VSWR of the ADE-TSA.

\section{Fabrication and Experiment of the Integrated Unit}

Because both of the Rotman lens and the ADE-TSA obtained in Sections 2 and 3 have microstrip line ports of the same size, they can be designed on a single PCB and connected seamlessly. An integrated unit made up of a printed Rotman lens and an antenna array of eight ADE-TSA elements is designed and fabricated on a Rogers RT/duroid 5880 PCB (thickness is $0.508 \mathrm{~mm}$ ); then the integrated unit is assembled in a metal cavity for measuring as shown in Figure 9. During the measurement all the unused beams are terminated with $50 \Omega$ loads. The isolation results between several ports are measured from $12 \mathrm{GHz}$ to $18 \mathrm{GHz}$ and shown in Figure 10 . Most of the isolation values $(\mathrm{dB})$ fall in an interval from $-15 \mathrm{~dB}$ to $-20 \mathrm{~dB}$, comparable to that in $[15,16]$. The voltage standing wave ratios (VSWR) of the beams ports are also measured and shown in Figure 11. It can be seen that the 


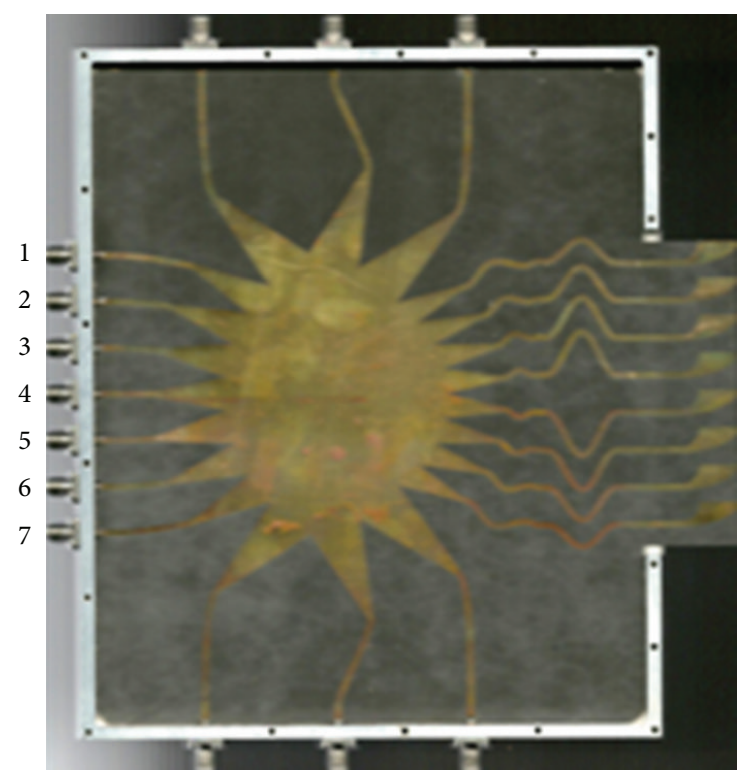

FIGURE 9: The integrated unit.

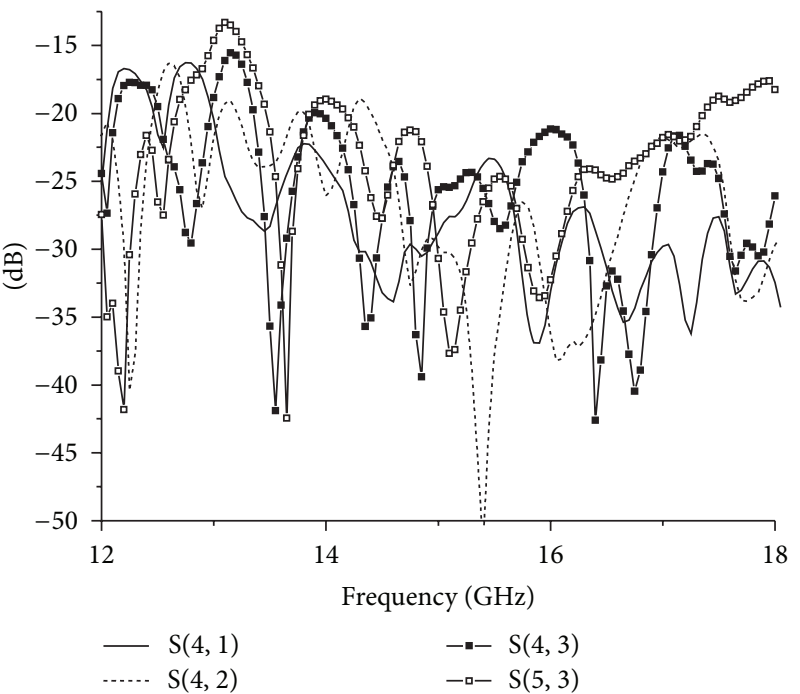

FIGURE 10: Isolation of the Rotman lens beam ports.

VSWR values of all the beam ports are below 1.8 in the whole frequency band, which is satisfactory in most engineering applications. The radiation pattern of the integrated unit is also measured at $15 \mathrm{GHz}$ and is shown in Figure 12. The seven beams corresponding to the radiation/receiving beams when incident at beam ports $1 \sim 7$, respectively, it is clear that the integrated unit can generate satisfactory multiple beams.

\section{Conclusion}

In this paper, a printed Rotman lens and an ADE-TSA array are studied at first; on the basis of this study, an integrated unit composed of the Rotman lens and the ADE-TSA array is designed on a single PCB and fabricated. Because both of the Rotman lens and the ADE-TSA have microstrip line ports

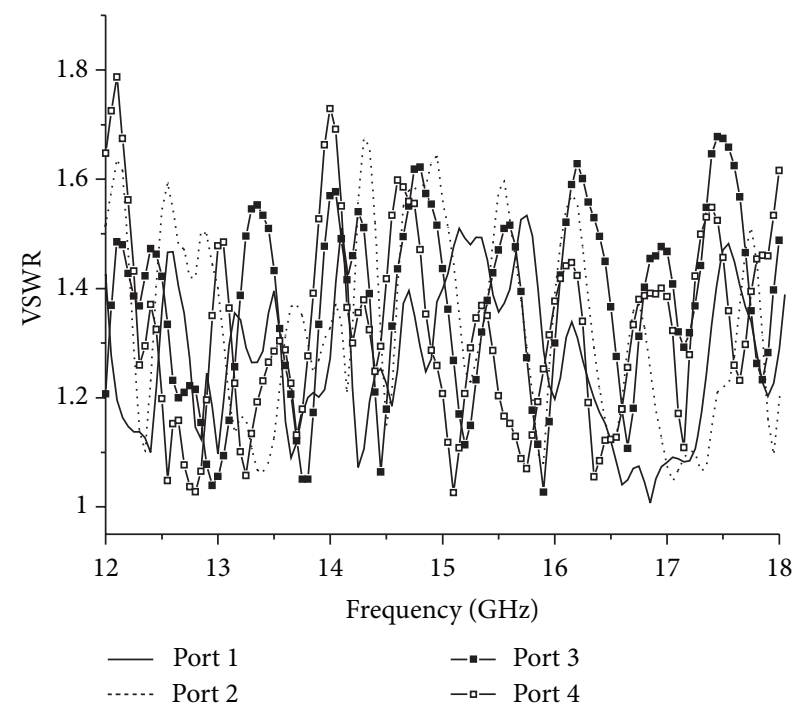

FIGURE 11: Reflection characteristics of Rotman lens beam ports.

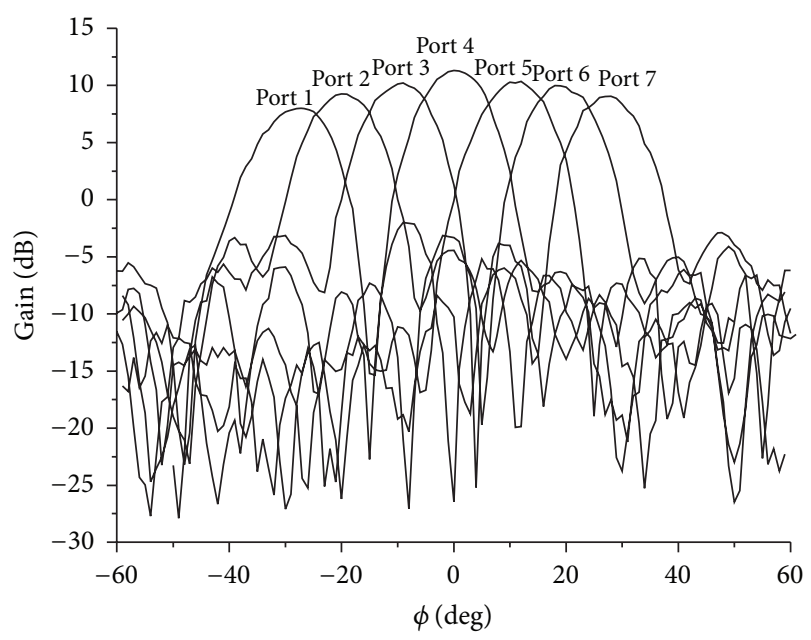

FIgURE 12: Multibeam pattern of the integrated unit at $15 \mathrm{GHz}$.

of the same size, they are connected seamlessly. Measured results are presented, which show that the integrated unit has good port and multiple beam characteristics. The integrated unit is a good candidate for multibeam antennas, because it is easy to fabricate, of low cost, and compact.

\section{Acknowledgments}

This paper is supported by NSFC 61071046 and is jointly supported by Aeronautical Science Foundation and RF simulation Key Lab of Avionics System.

\section{References}

[1] O. Kilic and S. Weiss, "Dielectric rotman lens design for multifunction RF antenna applications," in IEEE Antennas and Propagation Society Symposium, vol. 1, pp. 659-662, June 2004. 
[2] L. Schulwitz and A. Mortazawi, "A compact dual-polarized multibeam phased-array architecture for millimeter-wave radar," IEEE Transactions on Microwave Theory and Techniques, vol. 53, no. 11, pp. 3588-3594, 2005.

[3] W. Rotman and R. Turner, "Wide-angle microwave lens for line source applications," IEEE Transactions on Antennas and Propagation, vol. 11, no. 6, pp. 623-632, 1963.

[4] L. Musa and M. S. Smith, "Microstrip port design and sidewall absorption for printed Rotman lenses," IEE Proceedings $H$ : Microwaves, Antennas and Propagation, vol. 136, no. 1, pp. 53$58,1989$.

[5] B. Carlegrim and L. Pettersson, "Rotman lens in microstrip technology," in Proceedings of the 22nd European Microwave Conference, pp. 882-887, August 1992.

[6] J. Kim, C. S. Cho, and F. S. Barnes, "Dielectric slab Rotman lens for microwave/millimeter-wave applications," IEEE Transactions on Microwave Theory and Techniques, vol. 53, no. 8, pp. 2622-2627, 2005.

[7] L. Schulwitz and A. Mortazawi, "A new low loss Rotman lens design using a graded dielectric substrate," IEEE Transactions on Microwave Theory and Techniques, vol. 56, no. 12, pp. 27342741, 2008.

[8] Y. J. Cheng, W. Hong, K. Wu et al., "Substrate integrated waveguide (SIW) Rotman lens and its Ka-band multibeam array antenna applications," IEEE Transactions on Antennas and Propagation, vol. 56, no. 8, pp. 2504-2513, 2008.

[9] T. Katagi, S. Mano, and S. I. Sato, "An improved design method of Rotman lens antennas," IEEE Transactions on Antennas and Propagation, vol. 32, no. 5, pp. 524-527, 1984.

[10] R. C. Hansen, “Design trades for Rotman lenses," IEEE Transactions on Antennas and Propagation, vol. 39, no. 4, pp. 464-472, 1991.

[11] P. J. Gibson, “The Vivaldi Aerial," in Proceedings of the 9th European Microwave Conference, pp. 101-105, 1979.

[12] K. S. Yngvesson, D. H. Schaubert, T. L. Korzeniowski, E. L. Kollberg, T. Thungren, and J. F. Johansson, "Endfire tapered slot antennas on dielectric substrates," IEEE Transactions on Antennas and Propagation, vol. 33, no. 12, pp. 1392-1400, 1985.

[13] E. Gazit, "Improved design of the vivaldi antenna," IEE Proceedings H: Microwaves, Antennas and Propagation, vol. 135, no. 2, pp. 89-92, 1988.

[14] X. Qing, Z. N. Chen, and M. Y. W. Chia, "Parametric study of ultra-wideband dual elliptically tapered antipodal slot antenna," International Journal of Antennas and Propagation, vol. 2008, Article ID 267197, 9 pages, 2008.

[15] J. Remez, E. Zeierman, and R. Zohar, "Dual-polarized tapered slot-line antenna array fed by Rotman lens air-filled ridge-port design," IEEE Antennas and Wireless Propagation Letters, vol. 8, pp. 847-851, 2009.

[16] J. Kim and F. S. Barnes, "Dielectric slab Rotman lens with tapered slot antenna array," IEE Proceedings Microwaves, Antennas and Propagation, vol. 152, no. 6, pp. 557-562, 2005. 

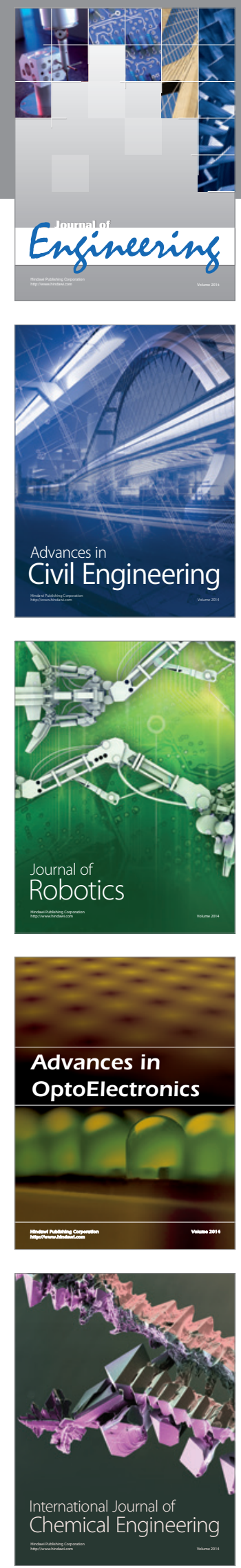

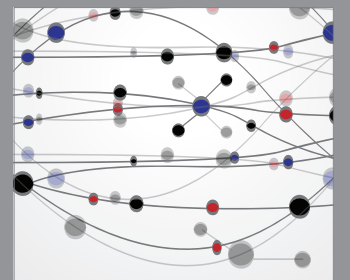

The Scientific World Journal
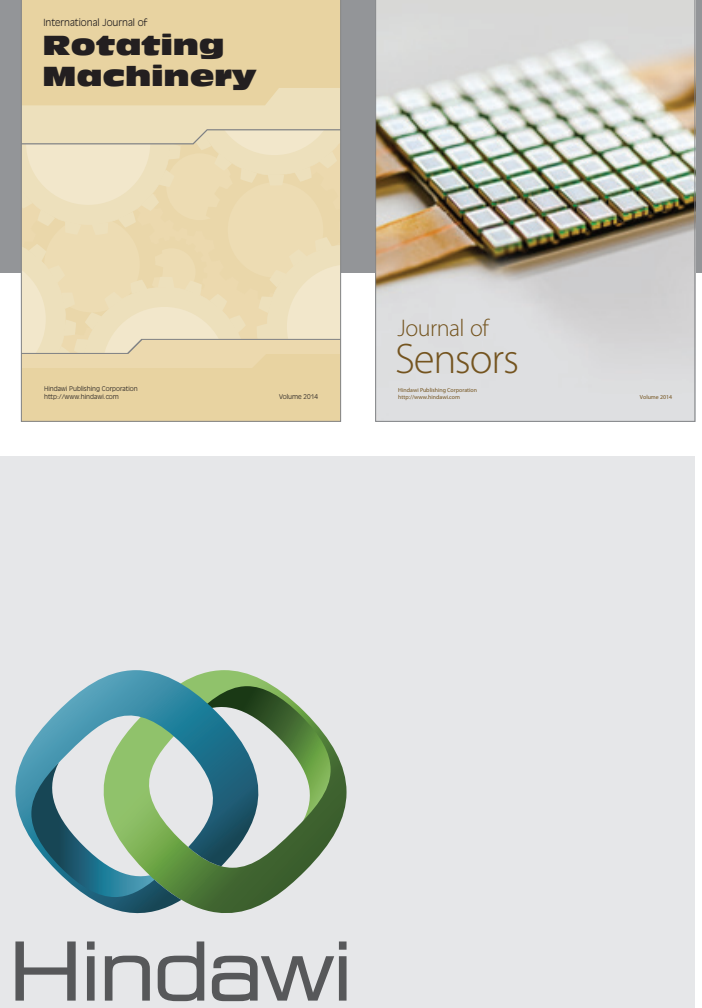

Submit your manuscripts at http://www.hindawi.com
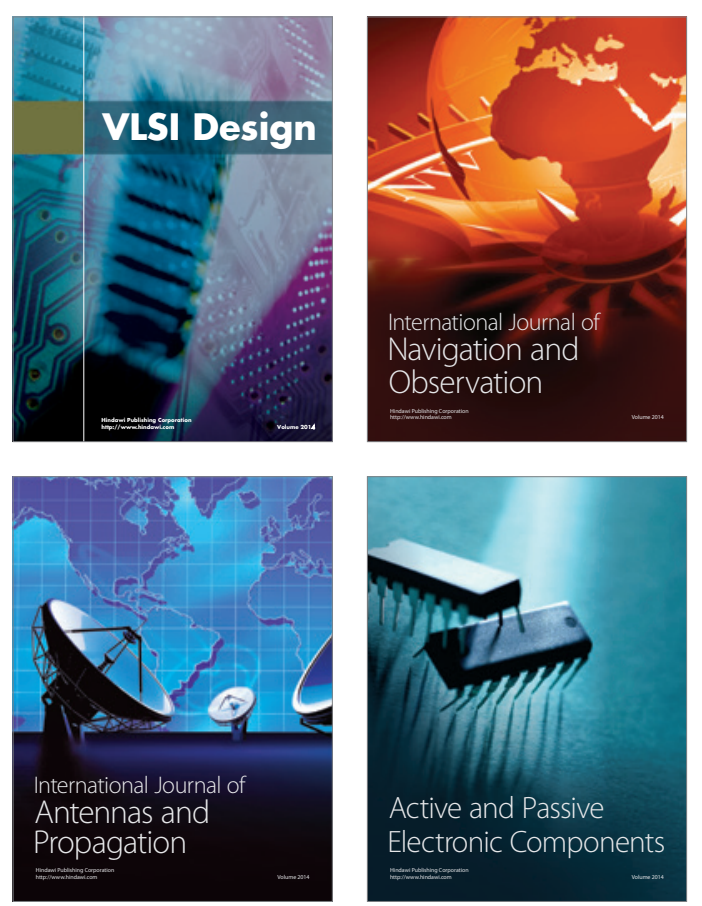
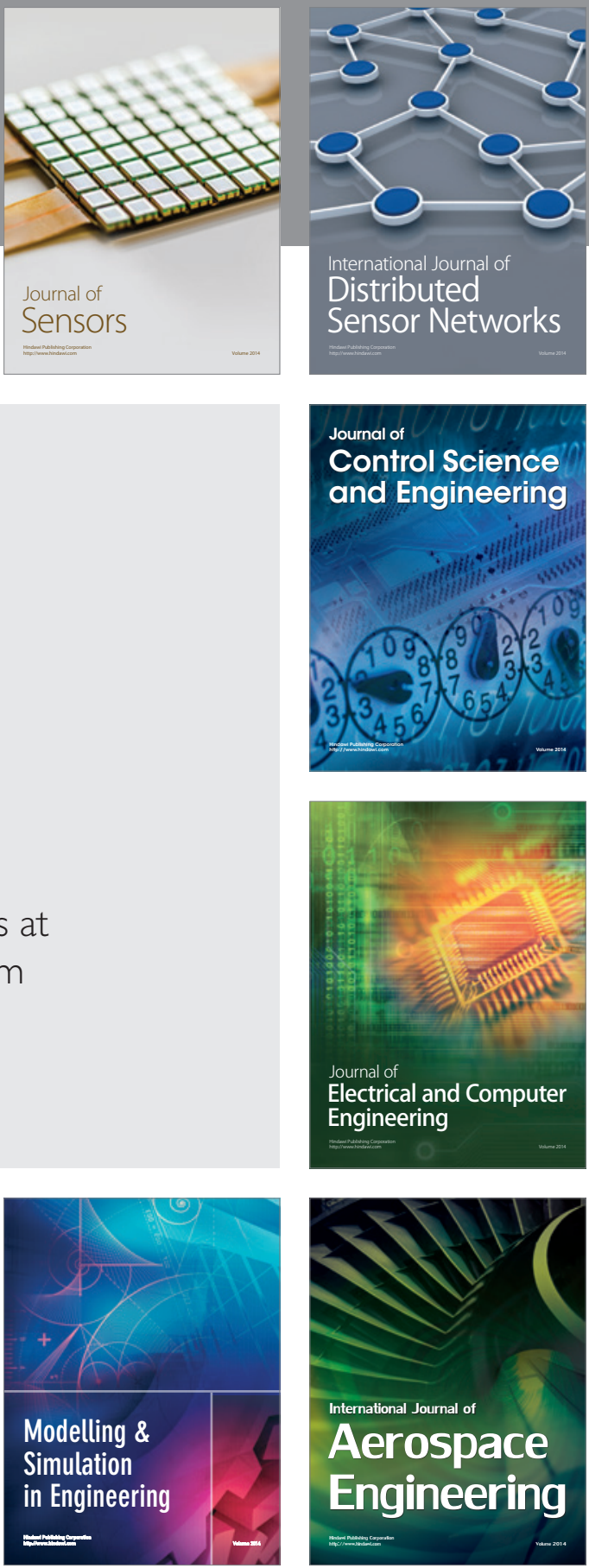

Journal of

Control Science

and Engineering
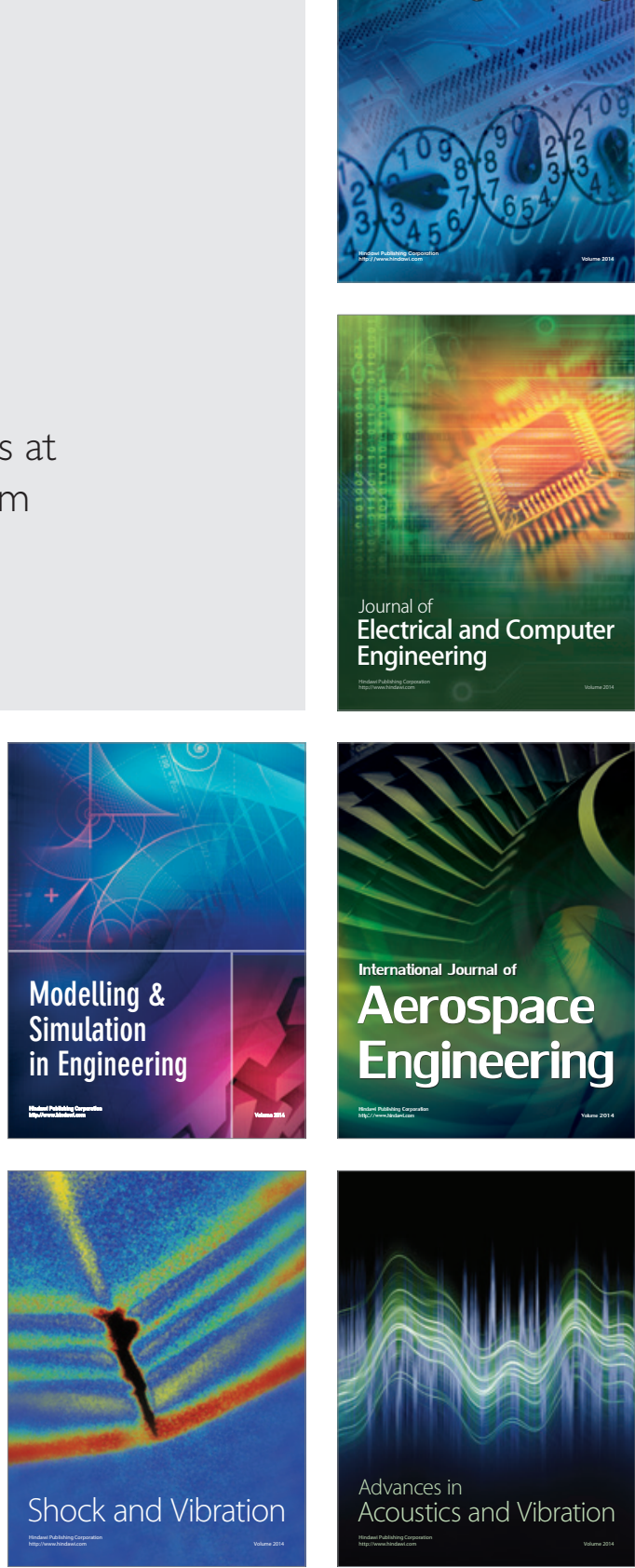